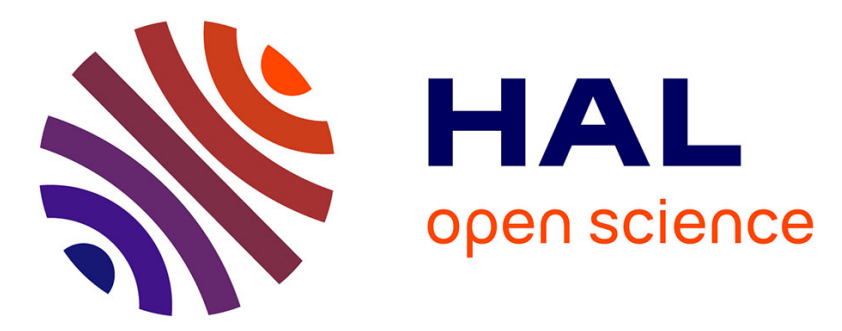

\title{
Microscopic work function anisotropy and surface chemistry of 316L stainless steel using photoelectron emission microscopy
}

N. Barrett, O. Renault, H. Lemaître, P. Bonnaillie, F. Barcelo, F. Miserque, M. Wang, C. Corbel

\section{To cite this version:}

N. Barrett, O. Renault, H. Lemaître, P. Bonnaillie, F. Barcelo, et al.. Microscopic work function anisotropy and surface chemistry of $316 \mathrm{~L}$ stainless steel using photoelectron emission microscopy. Journal of Electron Spectroscopy and Related Phenomena, 2014, 195, pp.117 - 124. 10.1016/j.elspec.2014.05.015 . cea-01376760

\section{HAL Id: cea-01376760 https://hal-cea.archives-ouvertes.fr/cea-01376760}

Submitted on 5 Oct 2016

HAL is a multi-disciplinary open access archive for the deposit and dissemination of scientific research documents, whether they are published or not. The documents may come from teaching and research institutions in France or abroad, or from public or private research centers.
L'archive ouverte pluridisciplinaire HAL, est destinée au dépôt et à la diffusion de documents scientifiques de niveau recherche, publiés ou non, émanant des établissements d'enseignement et de recherche français ou étrangers, des laboratoires publics ou privés. 


\title{
Microscopic work function anisotropy and surface chemistry of 316L stainless steel using photoelectron emission microscopy
}

\author{
N. Barrett ${ }^{\mathrm{a}, *}$, O. Renault ${ }^{\mathrm{b}}$, H. Lemaître ${ }^{\mathrm{c}, \mathrm{d}}$, P. Bonnaillie $^{\mathrm{e}}$, F. Barcelo ${ }^{\mathrm{f}}$,

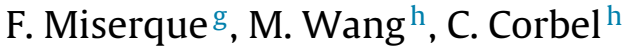 \\ a CEA, IRAMIS, SPEC, LENSIS, F-91191 Gif-sur-Yvette, France \\ b CEA, LETI, Minatec Campus, F-38054 Grenoble Cedex 09, France \\ ' Université de Cergy-Pontoise, Rue d'Eragny, Neuville sur Oise, 95031 Cergy-Pontoise, France \\ d Surface Dynamics Laboratory, Institut for Fysik og Astronomi Aarhus Universitet, Ny Munkegade 120, 8000 Aarhus C, Denmark \\ e CEA, DEN, DANS, DMN, SRMP, F-91191 Gif-sur-Yvette, France \\ ${ }^{f}$ CEA, DEN, DANS, DMN, SRMA, LA2M, F-91191 Gif-sur-Yvette, France \\ g CEA, DEN, DANS, DPC, SCCME, LECA, F-91191 Gif-sur-Yvette, France \\ h Laboratoire des Solides Irradis, Ecole Polytechnique, route de Saclay, F-91128 Palaiseau, France
}

\section{A R T I C L E I N F O}

\section{Article history:}

Received 4 April 2014

Received in revised form 26 May 2014

Accepted 28 May 2014

Available online 2 July 2014

\section{Keywords:}

Austenitic steel

Work function

X-ray photoelectron emission microscopy

EBSD

X-ray photoelectron spectroscopy

\begin{abstract}
A B S T R A C T
We have studied the variation in the work function of the surface of sputtered cleaned 316L stainless steel with only a very thin residual oxide surface layer as a function of grain orientation using X-ray photoelectron emission microscopy (XPEEM) and Electron Backscattering Diffraction. The grains are mainly oriented [ 1111 ] and [ 10101 . Four distinct work function values spanning a $150 \mathrm{meV}$ energy window are measured. Grains oriented [1 111 ] have a higher work function than those oriented [1 011 ]. From core level XPEEM we deduce that all grain surfaces are $\mathrm{Cr}$ enriched and $\mathrm{Ni}$ depleted whereas the $\mathrm{Cr} / \mathrm{Fe}$ ratio is similar for all grains. The [1 11] oriented grains show evidence for a $\mathrm{Cr}_{2} \mathrm{O}_{3}$ surface oxide and a higher concentration of defective oxygen sites.
\end{abstract}

(c) 2014 Elsevier B.V. All rights reserved.

\section{Introduction}

The corrosion resistance of stainless steels is a key element in their reliable use in aggressive environments. Austenitic stainless steel is widely used because it combines hardness and corrosion resistance. The corrosion resistance stems from the $\mathrm{Cr}$ rich composition, allowing a native $\mathrm{Cr}_{2} \mathrm{O}_{3}$ surface layer to be formed creating a passivation barrier to further corrosion.

One major challenge is to understand the influence of the polycrystalline grain structure on microscale spatial variations in the surface chemistry. X-ray photoelectron spectroscopy (XPS) is ideally suited to high resolution chemical analysis and, thanks to the typical inelastic mean path of photoelectrons, is intrinsically surface sensitive. However, typical X-ray beam spots used for standard XPS, including those produced by synchrotron radiation, are $0.1-1 \mathrm{~mm}$, whereas typical grain sizes are $\sim 1-10 \mu \mathrm{m}$.

\footnotetext{
* Corresponding author. Tel.: +33 169083272; fax: +33 169088446.

E-mail address: nick.barrett@cea.fr (N. Barrett).
}

Thus simultaneous spatial resolution beyond standard XPS ones and spectroscopic resolution is required.

Laboratory based XPS imaging instruments go some way to providing a solution to this problem. The imaging properties of a hemispherical analyzer are used to generate energy filtered maps of the photoemitted electrons. The entrance lenses accept a field of view (FoV) of several hundred microns and are capable to transmit a sufficiently large phase space to enable elemental mapping in reasonable time, albeit with only limited lateral resolution $\sim 50 \mu \mathrm{m}$. Such systems have been used for chemical imaging of austenitic steels [1] and Iconel 600 alloys [2].

A second class of instruments is derived from photoemission or low energy electron microscopes [3] that provides and aims for the highest lateral resolution in surface analysis within a small field of view is derived from photoemission or low energy electron microscopes [3]. However, a direct consequence of the high lateral resolution is a considerably reduced overall transmission of the electron energy analyzer. Recently, spectroscopic PEEM in the laboratory has become available with a new generation of XPEEM instruments fitted with high-transmission, band-pass energy filters [4]. Spectroscopic XPEEM is possible with a bright, laboratory X-ray 
source [5], enabling a new kind of parallel XPS imaging method in which the PEEM column acts as the entrance lens of the imaging electron energy spectrometer. Lateral resolutions of $0.5 \mu \mathrm{m}$ using a focused laboratory X-ray sources, have been demonstrated [6].

PEEM imaging of the outward diffusion of $\mathrm{Cr}$ and $\mathrm{Cr}_{2} \mathrm{O}_{3}$ through C precipitates in commercial 304 grade stainless steel has been reported [7]. The initial precipitates were smaller than $10 \mu \mathrm{m}$, showing the need for high spatial resolution to characterize the chemistry of the first steps of corrosion. Oxidation phenomena on Laves phase forming Ti-Nb stabilized ferritic stainless steel have also been studied using PEEM, demonstrating the role of $\mathrm{Nb}$ and $\mathrm{Si}$ in interfacial oxidation [8].

Less attention has been paid to the role of the crystallographic orientation of the grains on work function, despite the fact that the work function anisotropy due to grain orientation is well known [9]. In fact, the work function depends on the surface electron affinity. For example, based on XPEEM data, it has been shown for polycrystalline copper that the denser the surface, the higher the work function [10]. Such variations could play an important role in determining the electrochemistry of the initial stages of corrosion. Grain dependent surface alloying of palladium and nickel has been studied using micro-probe low energy electron diffraction and scanning photoelectron microscopy [11].

In this paper we report on the study of the surface chemistry of as-received $316 \mathrm{~L}$ stainless steel using XPS, XPEEM, scanning electron microscopy (SEM) and electron back-scattering diffraction (EBSD). The combined use of XPS and XPEEM provides a multiscale chemical analysis over three orders of magnitude, from $1 \mathrm{~mm}$ to $1 \mu \mathrm{m}$. The SEM images give topological information on the surface and sub-surface, while the EBSD furnishes the crystallographic orientation of the individual steel grains.

\section{Experiment}

The as-received, mechanically and chemically polished stainless steel sample (composition Fe 68.18, Cr 16.6, Ni 10.2, Mo 2.21, Mn 1.82, Cu 0.43, Si 0.3, Co 0.11, N 0.056, P 0.033, C 0.03, S 0.028 mass\%) was cut to the appropriate size for the analysis. Preliminary XPS characterization showed that the cutting process did not influence the surface chemistry. Before insertion into the ultra-high vacuum (UHV) of the XPEEM system, the sample was cleaned in an ultrasound bath for $3 \mathrm{~min}$ using acetone then for $3 \mathrm{~min}$ using iso-propanol.

In the UHV preparation chamber the sample was then cleaned using $1 \mathrm{kV} \mathrm{Ar}{ }^{+}$ion sputtering for $35 \mathrm{~min}$ with a partial pressure $P_{\mathrm{Ar}}=3.8 \times 10^{-4} \mathrm{~Pa}$, giving a ion current density of $14 \mu \mathrm{A} / \mathrm{cm}^{2}$. To repair surface disorder induced by the ion beam sputtering beam, the sample was then annealed for $30 \mathrm{~min}$ at $550{ }^{\circ} \mathrm{C}$ in a pressure $P=4.9 \times 10^{-7} \mathrm{~Pa}$. There is no residual oxygen in the chamber; therefore no significant additional oxidation is expected. We estimate that the sputtering removes $2.0-3.0 \mathrm{~nm}$, close to the expected thickness of the native $\mathrm{Cr}_{2} \mathrm{O}_{3}$ oxide film. This is consistent with the results shown below that indicates that the observed surface chemistry corresponds to a metallic surface with residual oxidation rather than to an oxide surface.

The XPS imaging instrument is a NanoESCA spectromicroscope [4], consisting of a fully electrostatic PEEM electron-optical column coupled with a double hemispherical analyzer for energy filtering [12]. The limit to the lateral resolution is given by the chromatic aberrations of the objective lens of the PEEM column, and is theoretically around $20 \mathrm{~nm}$. Two specific important features of the XPEEM instrument enable an efficient collection of core level electrons signal, making possible both high spatial and energy resolution in laboratory conditions: first, a bright monochromatic X-ray source and second, the a double hemispherical analyzer which acts as a high-transmission imaging spectrometer.

The monochromator of the X-ray source delivers $\mathrm{Al} \mathrm{K} \alpha_{1}$ radiation $(1486.7 \mathrm{eV}$ photon energy, photon band width $0.26 \mathrm{eV}$ and photon flux on the sample $\sim 10^{12}$ photons/( $\left.\mathrm{s} \mathrm{mm}^{2}\right)$. The X-ray beam is incident at $65^{\circ}$ with respect to the surface normal, and the spot size can be adjusted between 30 and $200 \mu \mathrm{m}$. The two hemispherical analyzers are coupled by a transfer lens [4]: the second analyzer corrects for the spherical aberrations of the first one $\left(\alpha^{2}\right.$-term) and allows the operation at low pass energies without deteriorating the spatial resolution. XPS spectroscopy in the field of view of the PEEM microscope ( $\mu$-XPS) can also be performed by using only the first hemispherical analyzer and a channeltron detector. Thus it is possible to switch from PEEM spectroscopic imaging with sub-micron spatial resolution to area-averaged XPS over a $100 \mu \mathrm{m}$ field of view in the same XPEEM instrument.

Threshold PEEM images were acquired using both $\mathrm{Hg}$ ultraviolet light $(4.9 \mathrm{eV})$ and the focused $\mathrm{Al} \mathrm{K} \alpha \mathrm{X}$-ray source. The photoelectron energy is measured on the scale $E-E_{\mathrm{F}}$, where $E_{\mathrm{F}}$ is the sample Fermi level. The work function is therefore directly given by the energy position of the photoemission threshold. Image series were acquired in $0.025 \mathrm{eV}$ steps from $2.5-6.0 \mathrm{eV}$ to $3.5-10.0 \mathrm{eV}$, respectively. The analyzer slit width was set to $1 \mathrm{~mm}$ and a pass energy of $100 \mathrm{eV}$ was used, giving a spectroscopic resolution of $0.4 \mathrm{eV}$. Acquisition time was $10 \mathrm{~s}$ per image, repeated twice. In both cases a field of view (FoV) of $115 \mu \mathrm{m}$ was used. The contrast aperture was set at $150 \mu \mathrm{m}$ giving a lateral resolution of about $150 \mathrm{~nm}$.

XPEEM images for core electrons were acquired using the focused $\mathrm{Al} \mathrm{K} \alpha$ X-ray source. For the Fe and $\mathrm{Cr} 2 \mathrm{p}$ core level image series, images were acquired in $0.25 \mathrm{eV}$ steps. The entrance slit was set at $2 \mathrm{~mm}$ and the pass energy $100 \mathrm{eV}$, corresponding to an energy resolution of $0.8 \mathrm{eV}$. The exposure time was $5 \mathrm{~min}$ per image and the contrast aperture set at $500 \mu \mathrm{m}(0.5 \mu \mathrm{m}$ lateral resolution). Nine such image series were summed. The 01 s core level image series was recorded using $0.2 \mathrm{eV}$ steps and a total of 12 series were summed. The inelastic mean free path of the $\mathrm{Cr}$, Fe and Ni 2p core level electrons is $\sim 1-2 \mathrm{~nm}$.

PEEM transmission has an additional $1 / E$ dependence with respect to standard XPS analyzers. Furthermore, core level intensity is typically two orders of magnitude lower than the secondary electron peak. As a result, the core level signal is much lower than at threshold. The PEEM images have been corrected for detector inhomogeneity and topographical effects by dividing by a flat field image obtained at $E-E_{\mathrm{F}}$ far from a characteristic peak using defocussed electron optics. Camera noise is removed by subtraction of a dark field image obtained using the same acquisition time as the real images but with the PEEM optics switched off. These procedures are equivalent to the background substraction and normalization procedure described in Ref. [2]. The threshold PEEM images must also be corrected for the intrinsic non-isochromaticity due to the dispersive action of the hemispherical analyzer [13]. For the photoemission energy threshold, this was done using a customized software procedure which calculates the dispersion as a function of the vertical coordinate in an image stack, obtains a best fit using a parabolic function and adjusts vertical slices of the stack accordingly. The same correction was not possible for the core level image series since the energy step $(0.25 \mathrm{eV}$ for $\mathrm{Fe}$ and $\mathrm{Cr} 2 \mathrm{p}, 0.2 \mathrm{eV}$ for $\mathrm{O} 1 \mathrm{~s}$ ) was comparable to the expected nonisochromaticity. However, the correction is negligible with respect to the spectroscopic resolution of the core level imaging.

The microstructure was studied using a scanning electron microscope (FEG LEO 1525) at CEA Saclay. The Electron backscattering diffraction was carried out using a MEB FEG JSM7001F LV with a high resolution electron Flash (BRUKER) and QUANTAX CrystAlign analysis programme. $1200 \times 900$ pixel maps with $\times 900$ magnification $(0.11 \mu \mathrm{m} /$ pixel $)$ were acquired. 

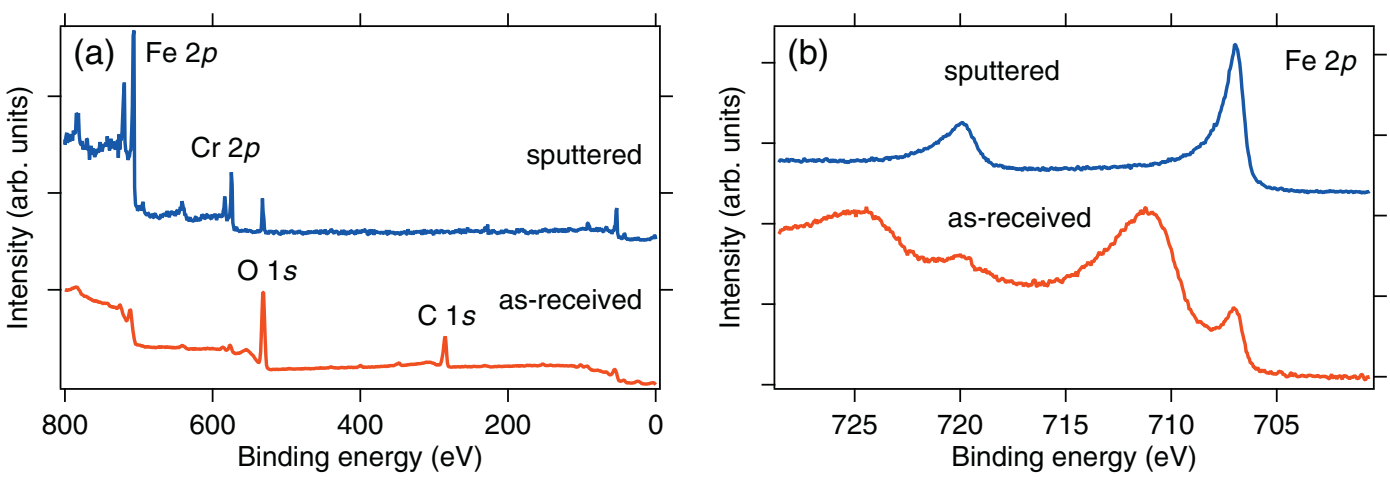

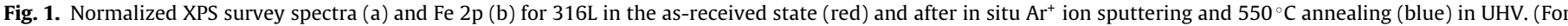
interpretation of the references to color in this legend, the reader is referred to the web version of the article.)

\section{Results and discussion}

\subsection{Work function and grain orientation}

The comparison of the area-averaged XPS survey spectra in Fig. 1a before and after cleaning illustrates the effect of the UHV $\mathrm{Ar}^{+}$sputtering and $550{ }^{\circ} \mathrm{C}$ annealing in vacuum of the $316 \mathrm{~L}$ stainless steel surface. One the one hand, the $C 1 \mathrm{~s}$ peak at $\sim 285 \mathrm{eV}$ binding energy has virtually disappeared and the $O 1$ s peak at $\sim 532 \mathrm{eV}$, close to those found in $\mathrm{Ni}$, Fe or $\mathrm{Cr}$ related oxides is strongly attenuated [14]. On the other hand, the metallic peaks at energy characteristic for $\mathrm{Cr}$, Fe and Ni 2p [1] become much stronger. As illustrated by the high resolution Fe 2 p spectrum in Fig. 1 b, the oxide related emission at 711 and $725 \mathrm{eV}$ has been strongly attenuated and the spectrum is dominated by emission from the metallic Fe. We will see below that there is nevertheless still some residual oxide at the surface. The quasi-extinction of the peak for oxidised Fe after cleaning shows that, as expected, the sputtering has removed most of the native oxide. It also confirms that the value of the sputtering rate has been correctly estimated.

Quantitative interpretation of the core level spectra can be considerably complicated by the fact that in transition metal species such as $\mathrm{Fe}(\mathrm{III})$ and $\mathrm{Cr}(\mathrm{III})$, the unpaired d electron gives rise to multiplet states and shake-up satellites [14] in addition to the chemical shifts induced by the oxidation. Indeed, the unsputtered spectrum in Fig. 1b is similar to those shown in Ref. [14] but after sputtering the oxide has been almost completely removed, the contribution of the unpaired electron induced multiplet splitting to the spectral intensity is therefore expected to be negligible. In the following analysis, we will assume that the core level shifts to high binding energy in the metal 2 p spectra are due principally to oxidized metal atoms rather than multiplet states.

Fig. 2a shows a SEM secondary electron micrograph of the region of interest studied in PEEM obtained with a primary electron energy of $5 \mathrm{kV}$. The electrons are sensitive to changes in the grain surface chemistry and twinning is visible. The image of Fig. 2a can be compared to typical PEEM images obtained with UV Hg light excitation (Fig. 2b and c) for photoelectron kinetic energy, $E-E_{\mathrm{F}}$, values of 3.95 and $4.30 \mathrm{eV}$ close to threshold. A sharp grain structure is observed, with evidence for crystal twinning, see, for example, the near vertical bands in the upper right part of the images (marked with an arrow). For some (not all) of the grains, contrast inversion is observed between the two energies (see, for example, grains indicated by the dotted arrows). This is a clear signature of distinct photoemission threshold values, equivalent to work function variation from one grain to another. For other grains the intensity contrast does not change. Overall, the higher contrast obtained in spectroscopic PEEM near threshold compared with SEM arises from the enhanced surface sensitivity and the work function contrast mechanisms.

To map the work function, pixel by pixel fits to the threshold image series obtained using UV $\mathrm{Hg}$ and $\mathrm{Al} \mathrm{K} \alpha$ excitation have been performed using a complementary error function [10]. In both cases, with $2 \times 2$ binning, the full FoV contains some 300,000 spectra. The histograms of the work function values in Fig. $3 \mathrm{c}$ and $\mathrm{d}$ have been fitted with the minimum possible number of Gaussian distributions with identical $\sigma$ values (30 meV). Four distinct work function values are obtained with a 110-150 meV energy spread.

The $\mathrm{Hg}$ and $\mathrm{Al} \mathrm{K \alpha}$ WF maps have very similar distributions but that obtained using X-rays is shifted by $0.1 \mathrm{eV}$ to higher energy. The energy of the $\mathrm{Hg}$ source means that the threshold intensity comes mainly from direct transitions rather than true secondary electrons. As a result, the intensity distribution is modified, and may give rise to a shift in the threshold energy position. We therefore consider that the work function values obtained using X-ray excitation are more reliable.

The work function must also be corrected for the Schottky effect arising from the high extraction voltage [10] used in PEEM. For the experimental parameters used here one should add $0.098 \mathrm{eV}$ to the measured values. As a result, we determine the work function spread of the cleaned $316 \mathrm{~L}$ surface to be $4.92-5.06 \mathrm{eV}$. (a)

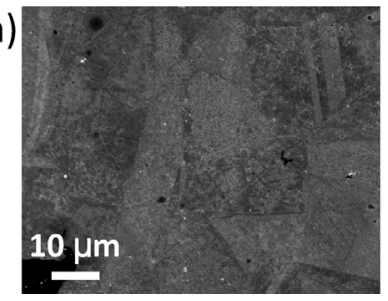

(b)



(c)

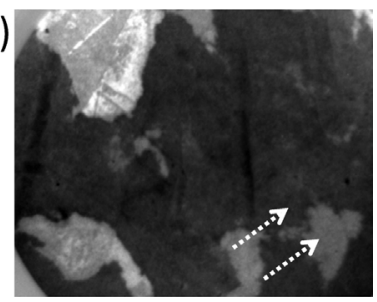



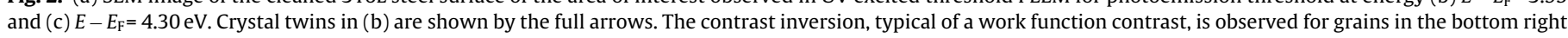
of images (b) and (c), indicated by the dotted arrows in (c). 
(a)
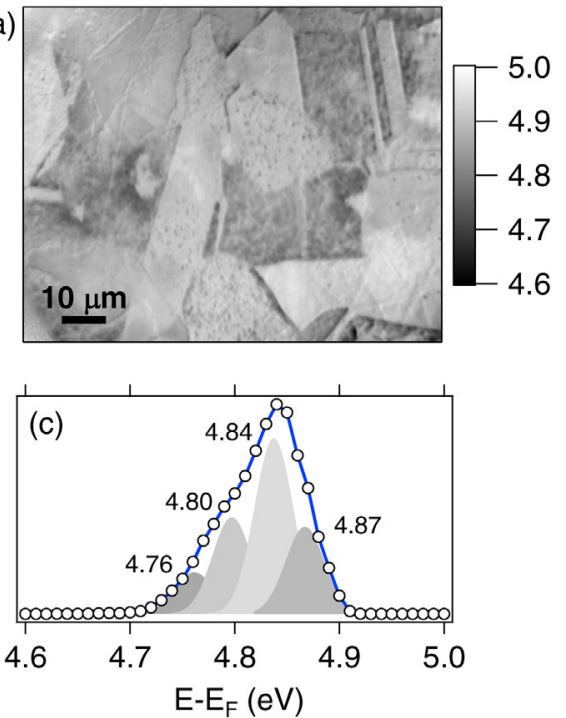

(b)
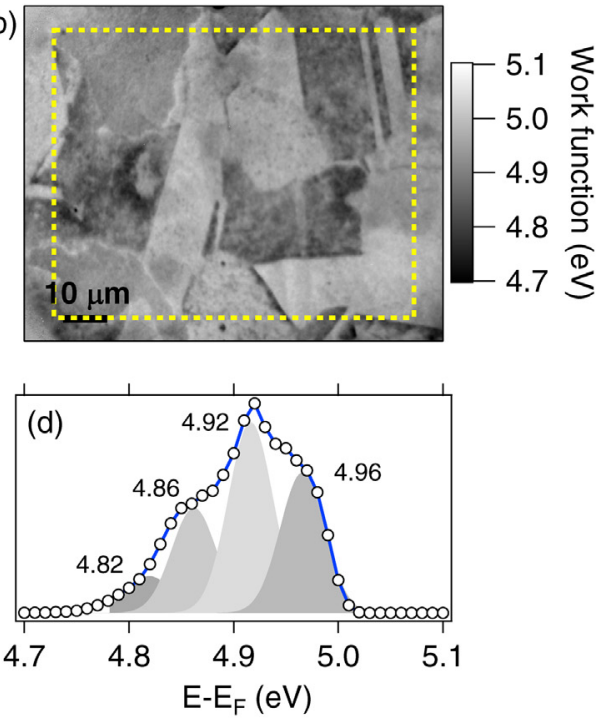



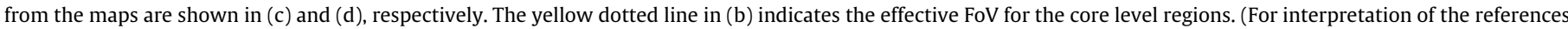
to color in this legend, the reader is referred to the web version of the article.)

Table 1

Binding energies (eV) and intensities obtained from best fits to the $\mathrm{Cr}$, Fe 2p, Ni 2p $\mathrm{p}_{3 / 2}$ and $\mathrm{O} 1 \mathrm{~s}$ core level spectra.

\begin{tabular}{|c|c|c|c|c|c|c|}
\hline \multirow[b]{2}{*}{$\mathrm{Cr} 2 \mathrm{p}_{3 / 2}$} & \multicolumn{3}{|c|}{ Binding energy $(\mathrm{eV})$} & \multicolumn{3}{|c|}{ Intensity } \\
\hline & 574.29 & 575.52 & 577.24 & 4222 & 1251 & 591 \\
\hline Fe $2 p_{3 / 2}$ & 707.04 & 707.98 & 709.67 & 6910 & 3151 & 1027 \\
\hline $\mathrm{Ni} 2 \mathrm{p}_{3 / 2}$ & 853.04 & 853.58 & - & 1307 & 695 & - \\
\hline $01 \mathrm{~s}$ & 531.34 & 532.70 & - & 1307 & 2428 & - \\
\hline
\end{tabular}

Fig. 4 shows the map of the crystal grain orientation as measured by EBSD. To facilitate comparison, the FoV analyzed in PEEM is enclosed by the white dotted rectangle in the EBSD orientation map. It can be seen that the surface is composed mainly of grains oriented along [ 10101$]$ and [1 111 ] directions. The comparison with the work function maps of Fig. 3 indicates that, on the one hand, the low work function grains are correlated with the [1 01 1] direction and, on the other hand, the high work function values are correlated with grains oriented along [111]. The increase in the work function with increasing surface atom density agrees qualitatively with, for example, similar experiments on polycrystalline copper [10].
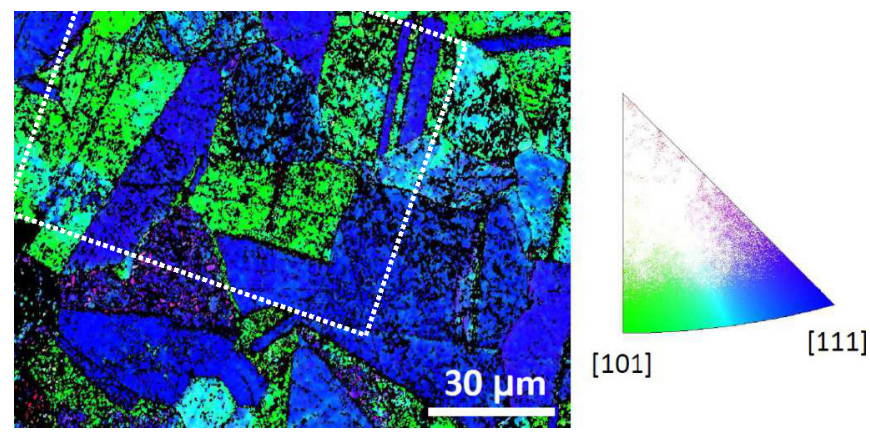

Fig. 4. Crystal grain orientation measured by EBSD. The dotted rectangles indicate the sample area analyzed in PEEM shown in Fig. 2 to facilitate comparison. Low work function is associated with the [ 10101 ] oriented grains whereas higher work function is found for the [111] orientation. (For interpretation of the references to color in the text, the reader is referred to the web version of the article.)

\subsection{Grain surface chemistry}

To clarify the chemistry surface associated to the work function distribution, we have studied the spatial variations in the core level emission from the same area as used for the threshold PEEM imaging. First, a $\mu$-XPS experiment has been performed in the FoV with the first hemispherical analyzer of the PEEM equipment and a single channeltron detector to record the area averaged 2 p core levels for $\mathrm{Cr}, \mathrm{Fe} \mathrm{Ni}$ and the $1 \mathrm{~s}$ core level for $\mathrm{O}$. The results are shown in Fig. 5. The $\mathrm{Cr}$ and $\mathrm{Fe} 2 \mathrm{p}_{3 / 2}$ and $2 \mathrm{p}_{1 / 2}$ peaks can both be detected (Fig. $5 \mathrm{a}$ and $\mathrm{b}$ ) whereas only the emission intensity from Ni $2 \mathrm{p}_{3 / 2}$ has a sufficiently strong signal (Fig. $5 \mathrm{c}$ ).

The core level spectra have been fitted using the XPS Peak 4.1 program which allows for easy use of both symmetric and asymmetric line-shapes and a Shirley background has been subtracted. As seen in Fig. 5, the best fits to the $2 \mathrm{p}_{3 / 2}$ peaks for $\mathrm{Cr}$, Fe and $\mathrm{Ni}$ are found using a single, main asymmetric line-shape with the addition of one or two symmetric components at higher binding energy. In Table 1 , the main peaks of the $2 \mathrm{p}_{3 / 2}$ level for $\mathrm{Cr}$, Fe and $\mathrm{Ni}$ correspond to binding energies of $574.3,707.0$ and $853.0 \mathrm{eV}$, in agreement with literature values for the metallic state [1]. Using tabulated X-ray sensitivity factors and the intensity in Table 1 for the main peaks and taking account of the additional $1 / E$ dependence of the PEEM transmission, we estimate that the composition at the surface (atomic \%) to be $\mathrm{Fe}(53.0), \mathrm{Cr}(42.0)$ and $\mathrm{Ni}(5)$. Compared to the nominal composition, there is therefore significant $\mathrm{Cr}$ enrichment $(+25)$ and $\mathrm{Fe}(-15)$ and $\mathrm{Ni}$ depletion $(-5)$. The mean free paths for $\mathrm{Cr}(1.1 \mathrm{~nm}), \mathrm{Fe}(1.1 \mathrm{~nm})$ et $\mathrm{Ni}(1.05 \mathrm{~nm})$ are virtually identical and therefore do not change the main result of the calculation which is the strong $\mathrm{Cr}$ surface enrichment whilst $\mathrm{Fe}$ and $\mathrm{Ni}$ are surface depleted. 

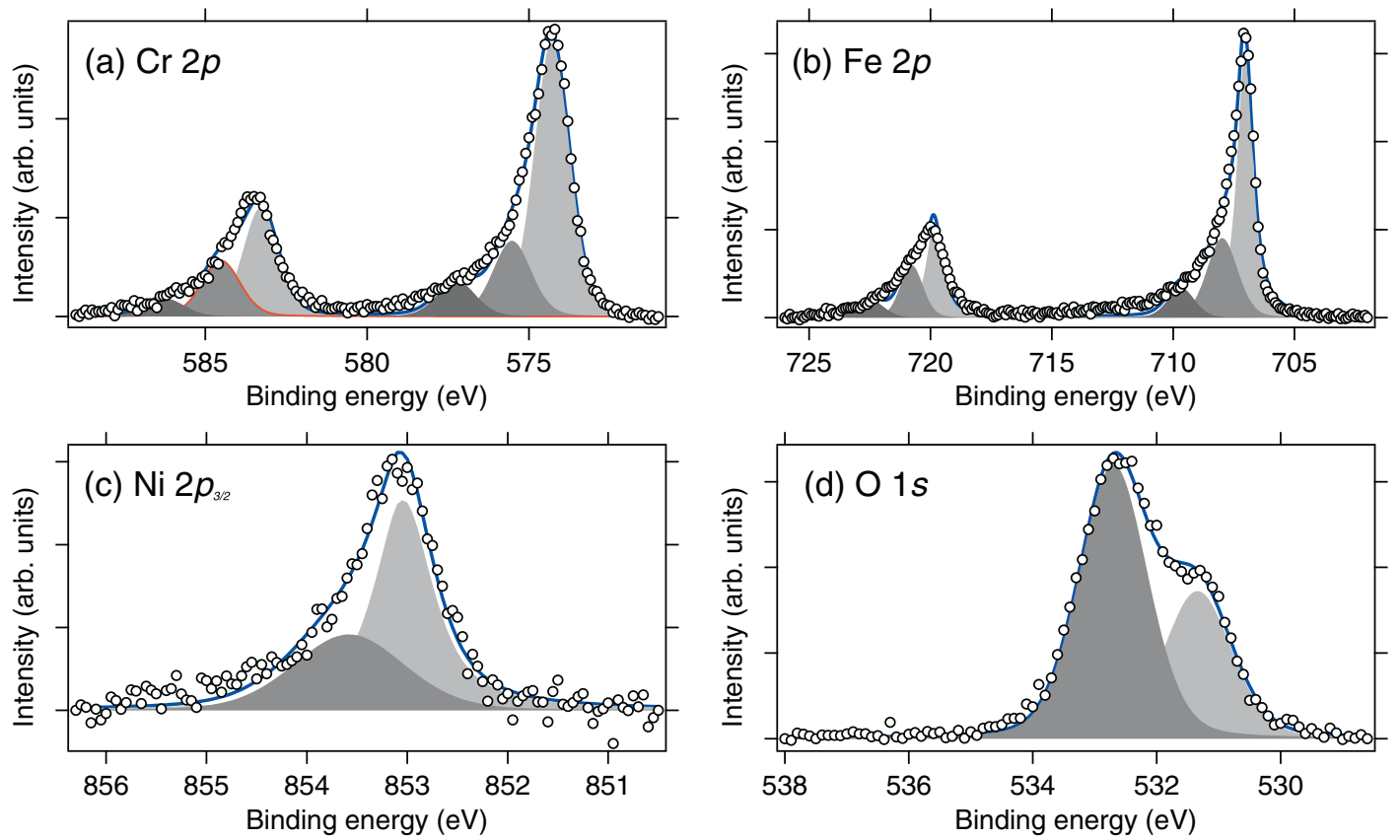

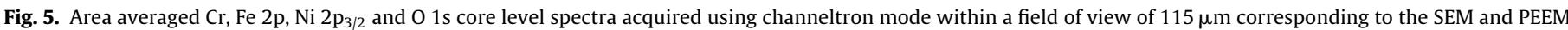
images in Fig. 2, together with best least squares fits (see text for details). For clarity, only every second experimental point is shown in the Cr and Fe core level spectra.

As seen in Fig. 5, the resolution of multi-component line-shapes for the $2 \mathrm{p} \mathrm{Cr}$, Fe and Ni core level peaks indicate that there are also some oxidized states. These weaker components at about $1-2 \mathrm{eV}$ higher binding energy for the $\mathrm{Cr}$ and $\mathrm{Fe} 2 \mathrm{p}_{3 / 2}$ core levels can be used to tentatively identified the residual oxidized states. On the basis of the data reported in Ref. [14] for different Cr or Fe related oxides and hydroxides, the energy shifts for $\mathrm{Cr}$ are of the order of those expected for $\mathrm{Cr}$ (II) oxide, $\mathrm{Cr}$ (III) hydroxide or the mixed $\mathrm{Fe}(\mathrm{II})-\mathrm{Cr}(\mathrm{III})$ oxide, chromite, $\mathrm{FeCr}_{2} \mathrm{O}_{4}$ or $\mathrm{Cr}\left(\mathrm{OH}^{-}\right)_{3}$. For Fe, they correspond to those reported for $\mathrm{Fe}(\mathrm{II})$ or $\mathrm{Fe}(\mathrm{III})$ oxides or chromite. For $\mathrm{Ni}$, the comparison with the data in Ref. [14] suggest the presence of the $\mathrm{Ni}(\mathrm{II})$ oxide, $\mathrm{NiO}$. From the relative intensities of the
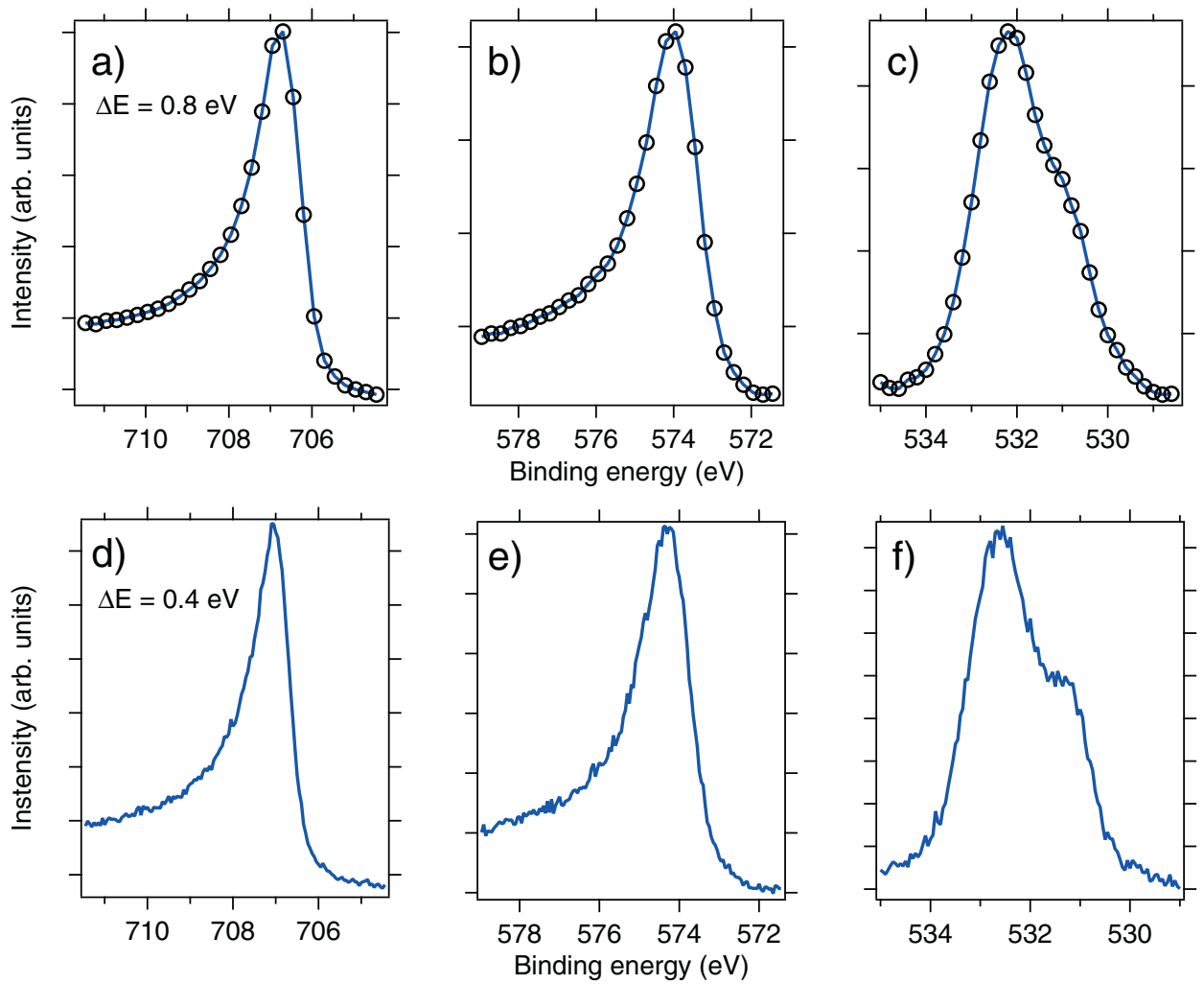




identical. 




Fig. 7. Threshold PEEM image of the field of view for the Fe $2 p, \mathrm{Cr} 2 \mathrm{p}$ and $\mathrm{O} 1 \mathrm{~s}$ core level imaging, showing the ROIs used to extract the local core level spectra. (For interpretation of the references to color in the text, the reader is referred to the web version of the article.)

components resolved in the peaks (Table 1) and considering the inelastic mean free path of the secondary electrons, it can be estimated that the oxide layer is indeed very thin, less than $1 \mathrm{~nm}$.

The 0 1s spectrum in Fig. 5d clearly has two components which are best fitted by a symmetric Gaussian-Lorentzian lineshape, showing that the oxygens occupy two chemical environments. The lower binding energy may correspond to $\mathrm{Cr}$, Fe, Ni hydroxydes $\mathrm{M}(\mathrm{OH})_{\mathrm{x}}$ according to Ref. [15] or to $\mathrm{Cr}$, Fe, Ni related oxides according to Ref. [14]. The higher binding energy may correspond to hydrated $\mathrm{Cr}$, Fe, Ni oxides according to Hanawa et al [15] or metal$\mathrm{OH}$ - bonding, expected to induce core level shifts between 1.3 [1] and $1.6 \mathrm{eV}$ [2] with respect to lattice oxygen sites. Given the dry UHV conditions under which the $316 \mathrm{~L}$ surface is cleaned, it seems unlikely that hydration may take place. The attribution of the lower binding energy to $\mathrm{Cr}$, Fe, Ni related oxides is consistent with the assignment of the $2 p$ core levels of these elements, as discussed in the preceding paragraph. One possibility for the higher binding energy peak is the presence of defective oxygen sites formed by the surface preparation (sputtering) used $[16,14]$.

We then performed core-level spectromicroscopy to study chemical variations between grains. To show the reliability of the data acquired in the imaging mode, the intensity across the whole FoV has been integrated for each core level series. The results are displayed in Fig. 6a-c for the Fe 2p, $\mathrm{Cr} 2 \mathrm{p}$ and $\mathrm{O}$ 1s core levels, where the points of the curves are the energies at which the core level images were acquired. The spectra can be compared with the area-averaged micro-spectra of Fig. 5 for the same energy window, shown in Fig. 6d-f. Apart from broadening due to the $0.8 \mathrm{eV}$ energy resolution used in imaging compared to $0.4 \mathrm{eV}$ in the $\mu$ XPS mode, the spectra are indeed identical, confirming that reliable information can be obtained from imaging despite the much lower statistics.

The regions of interest (ROIs) from which the local core level spectra are extracted are defined using the threshold PEEM image taken at $E-E_{\mathrm{F}}=3.95$, shown in Fig. 7. The image was chosen for maximum contrast enabling easy localization of different grains. The ROIs are on the same horizontal line to avoid nonisochromaticity effects when comparing the local spectra. They are centered on grains with high work function and grain orientation contrast. With reference to Fig. 4 , the 1 st, 2 nd, 4 th and 5 th ROI
Table 2

Work function corrected for Schottky effect, grain orientation as determined by EBSD, azimuthal angle and lattice to defective oxygen ratio for the 6 ROIs defined in Fig. 7.

\begin{tabular}{lllcl}
\hline ROI & Work function $(\mathrm{eV})$ & Orientation & Azimuth $\left({ }^{\circ}\right)$ & Lattice/defective \\
\hline 1 & 4.93 & {$\left[\begin{array}{lll}1 & 0 & 1\end{array}\right]$} & 0 & High \\
2 & 4.97 & {$\left[\begin{array}{lll}1 & 0 & 1\end{array}\right]$} & 0 & High \\
3 & 5.08 & {$\left[\begin{array}{lll}1 & 1 & 1\end{array}\right]$} & 0 & Low \\
4 & 4.98 & {$\left[\begin{array}{lll}1 & 0 & 1\end{array}\right]$} & 0 & High \\
5 & 4.94 & {$\left[\begin{array}{lll}1 & 0 & 1\end{array}\right]$} & 0 & High \\
6 & 5.02 & {$\left[\begin{array}{lll}1 & 1 & 1\end{array}\right]$} & 25 & Low \\
\hline
\end{tabular}

counting from the left are [ 10101$]$ oriented whereas the 3rd and 6th are [ $\left.\begin{array}{lll}1 & 1 & 1\end{array}\right]$ oriented.

The local $\mathrm{Cr} 2 \mathrm{p}_{3 / 2}$, Fe $2 \mathrm{p}_{3 / 2}$ and $\mathrm{O}$ 1s spectra of ROIs 1-6 in Fig. 7 are shown in Fig. 8a-c. From one ROI to another, one notices that the binding energy, shape and intensity of the peaks remains nearly unchanged for $\mathrm{Fe}$ and $\mathrm{Cr}$ whereas they vary for $\mathrm{O}$. This is an extremely interesting result since it shows that, despite the differences in work function and grain orientation, the near surface $\mathrm{Fe} / \mathrm{Cr}$ ratio, as probed by the spatially resolved XPS, remains constant. Both Fe $2 \mathrm{p}_{3 / 2}$ and $\mathrm{Cr} 2 \mathrm{p}_{3 / 2}$ spectra are almost wholly metallic.

Compared to the $\mathrm{Fe} 2 \mathrm{p}_{3 / 2}$ and $\mathrm{Cr} 2 \mathrm{p}_{3 / 2}$ intensity peaks, the local $\mathrm{O} 1 \mathrm{~s}$ intensity is very weak. This is consistent with the metallic character of the $2 p_{3 / 2}$ emission. It confirms that the ion sputtering removed almost the entire passivation oxide layer. However, the relative variations in both intensity and peak structure in the local $\mathrm{O} 1 \mathrm{~s}$ spectra are more significant than in the $\mathrm{Fe} 2 \mathrm{p}_{3 / 2}$ and $\mathrm{Cr} 2 \mathrm{p}_{3 / 2}$ spectra and indicate changes in the residual oxide layer, examined here in detail. The $\mathrm{O} 1 \mathrm{~s}$ are asymmetric, suggesting at least two distinct chemical environments. In the ROI 4 (green), there is a clear double peak structure corresponding to binding energies of 532.5 and $531 \mathrm{eV}$. The peak at higher binding energy is clearly resolved in each ROI although its shape and intensity vary. It has a fine structure for ROI 3 (blue) that is absent in the other ROIs. It is lower in intensity for the ROIs 1 (black), 2 (red) and 5 (magenta) than for the ROIs 3(blue), 4 (green) and 6 (orange). The peak at lower binding energy is more pronounced in ROI 4 than in the other ROIs. Its relative intensity is lowest for ROIs 3 and 6. Overall, the 01s spectra in ROIs 3 and 4 differ the most in shape whilst having similar total intensity.

The lower binding energy peak in the $01 \mathrm{~s}$ is attributed to lattice oxygen sites in $\mathrm{Fe}, \mathrm{Cr}$ or Ni related oxides. It is most clearly visible in ROI 4. It has been seen above that the $\mathrm{Fe} / \mathrm{Cr}$ ratio is constant over the ROIs. It seems consequently unlikely that the changes in the high binding energy component of the 01 s peak reflect changes in the residual oxide chemistry. We therefore conclude that defective oxygen sites can give rise to this component.

One question is whether the changes in the $01 \mathrm{~s}$ core level over the ROIs can be correlated to difference in the grain orientation of the ROIs. Comparison with the EBSD image in Fig. 4 shows the crystal orientation of the grain containing each ROI. The results are given in Table 2 . The right hand column gives a qualitative indication of the low to high binding energy intensity ratio of the 0 $1 \mathrm{~s}$ emission, in other words the ratio between lattice and defective oxygen sites. The ROIs 1, 2, 4 and 5 (green color code in Fig. 4) are oriented [ 101 ]. The ROIs 3 and 6 (blue color code in Fig. 4) are oriented [1 111 ]. The full EBSD data set shows that ROI 6 is rotated azimuthally (rotation axis perpendicular to the surface) by $25^{\circ}$ with respect to ROI 3. This may be the reason for the double structure in the high binding energy component, absent in ROI 6. It is interesting to note that both components of the $\mathrm{O} 1 \mathrm{~s}$ core level are lower in the [ $\left.\begin{array}{lll}1 & 0 & 1\end{array}\right]$ oriented grains (ROIs 1, 2 and 5). The low binding energy peak, attributed to lattice oxygen sites, is most prominent in the local spectra of the [ $\left.\begin{array}{lll}1 & 0 & 1\end{array}\right]$ oriented grains. The high binding energy peak, attributed to the defective oxygen sites, dominates for the 

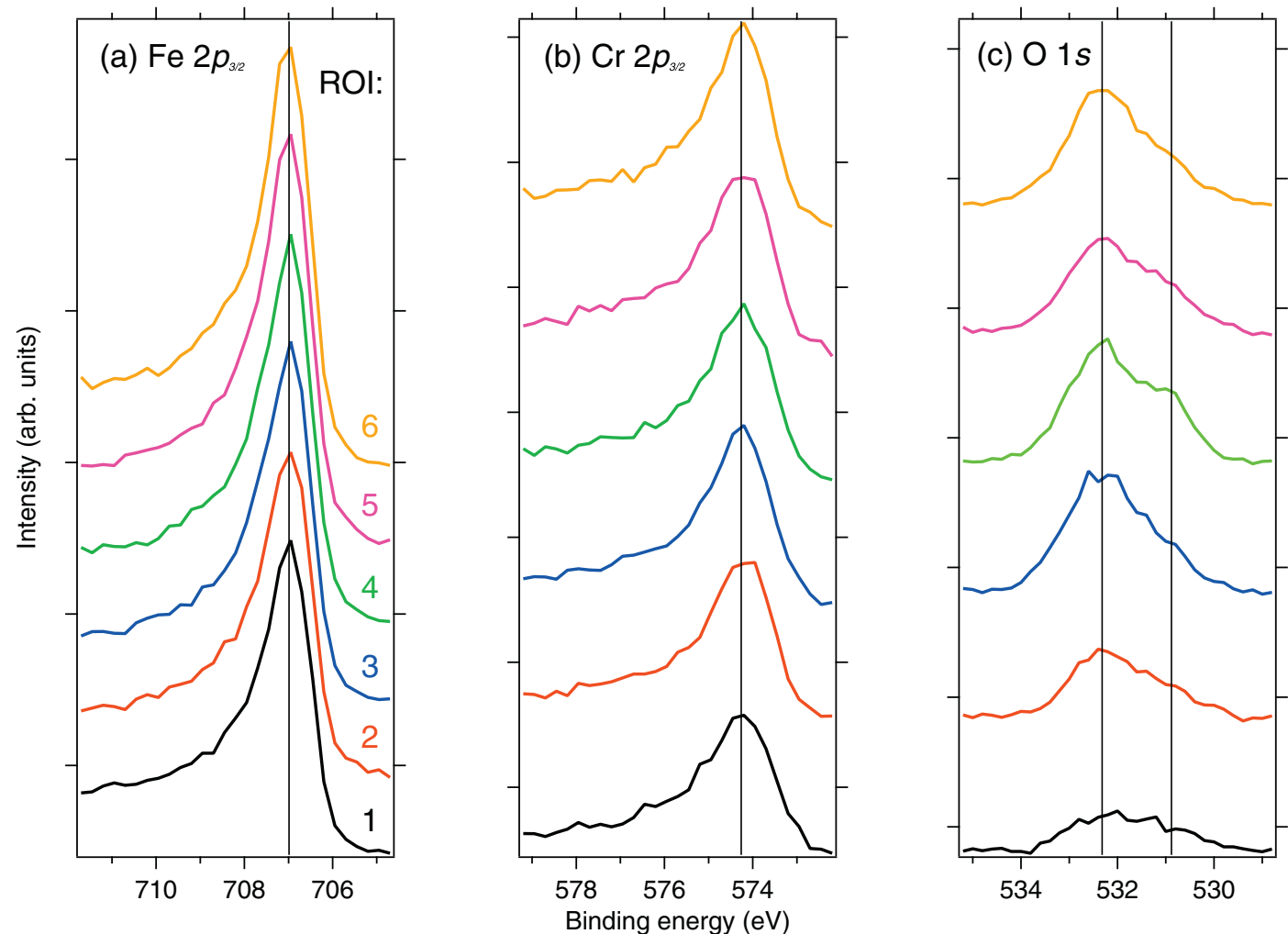

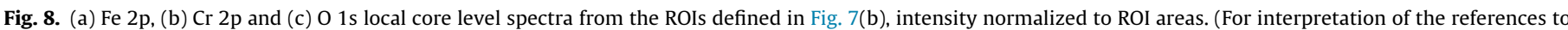
color in the text, the reader is referred to the web version of the article.)

[1 111 1] grains (ROI3 and ROI6). From the correlation between the features of the $01 \mathrm{~s}$ core level and the grain orientations, sputtering appears to be more effective for removing the oxide on the [1 01 ] grain than on the [ 1111 ] and also seems to favor the formation defective oxygen sites in [1 111 ] grains.

\section{Conclusions}

The combination of surface-sensitive X-ray photoelectron emission microscopy (XPEEM) and Electron Backscattering Diffraction provides refined understanding of the outermost surface properties of $316 \mathrm{~L}$ stainless steel at the micron scale. This results from the complementarity of the accessible information, in terms of structural, chemical and electronic properties. The work function information is of high sensitivity, since four distinct work function values spanning a $150 \mathrm{meV}$ energy window are measured, and provides images with a much higher contrast than SEM. Grains oriented [1 111 ] have a higher work function than those oriented [ 10101$]$ with the oriented [ 1111 ] and [ 10101$]$. From core level XPEEM we deduce that grain surfaces are $\mathrm{Cr}$ rich and $\mathrm{Ni}$ depleted whereas the $\mathrm{Cr} / \mathrm{Fe}$ ratio is similar for all grains. The [111] oriented grains show evidence for $\mathrm{Cr}_{2} \mathrm{O}_{3}$ surface oxide and a higher concentration of defective oxygen sites. Chemical variations due to the introduction of defective oxygen sites during sputtering may be responsible for further work function variations. The analytical method presented here should be of interest for a refined understanding of crystalline alloy surfaces and their interactions with complex environments.

\section{Acknowledgments}

We thank S. Foucquart for technical assistance with sample preparation. The work was supported by the CEA RACOC-2 programme. Part of the research was performed on the Nanocharacterization Platform of MINATEC, CEA-Grenoble.

\section{References}

[1] A. Rossi, B. Elsener, G. Hähner, M. Textor, N. Spencer, XPS, AES and ToF-SIMS investigation of surface films and the role of inclusions on pitting corrosion in austenitic stainless steels, Surf. Interface Anal. 29 (February) (2000) 460-467.

[2] B.A. Kobe, S. Ramamurthy, M.C. Biesinger, N.S. McIntyre, A.M. Brennenstühl, XPS imaging investigations of pitting corrosion mechanisms in Inconel 600, Surf. Interface Anal. 37 (5) (2005) 478-494, http://dx.doi.org/10.1002/sia.2038.

[3] E. Bauer, C. Koziol, G. Lilienkamp, T. Schmidt, Spectromicroscopy in a low energy electron microscope, J. Electron Spectrosc. Relat. Phenom. 84 (1997) 201-209.

[4] M. Escher, N. Weber, M. Merkel, C. Ziethen, P. Bernhard, G. Schönhense, S. Schmidt, F. Forster, F. Reinert, B. Krömker, D. Funnemann, Nanoelectron spectroscopy for chemical analysis: a novel energy filter for imaging X-ray photoemission spectroscopy, J. Phys. Condens. Matter 17 (16)(2005) S1329-S1338.

[5] O. Renault, N. Barrett, A. Bailly, L. Zagonel, D. Mariolle, J. Cezar, N. Brookes, K. Winkler, B. Krömker, D. Funnemann, Energy-filtered XPEEM with NanoESCA using synchrotron and laboratory X-ray sources: principles and first demonstrated results, Surf. Sci. 601 (20)(2007) 4727-4732 http://linkinghub.elsevier. com/retrieve/pii/S0039602807006085

[6] O. Renault, M. Lavayssière, A. Bailly, D. Mariolle, N. Barrett, Core level photoelectron spectromicroscopy with $\mathrm{Al} \mathrm{K} \alpha 1$ excitation at $500 \mathrm{~nm}$ spatial resolution, J. Electron Spectrosc. Relat. Phenom. 171 (1-3) (2009) 68-71 http://linkinghub. elsevier.com/retrieve/pii/S0368204809000711

[7] T.-H. Kang, K. Ihm, C.-C. Hwang, C. Jeon, K.-j. Kim, J.-Y. Kim, M.-K. Lee, H.-J. Shin, B. Kim, S. Chung, C.-Y. Park, Direct image observation of the initial forming of passive thin film on stainless steel surface by PEEM, Appl. Surf. Sci. 212-213 (2003) 630-635 http://linkinghub.elsevier.com/retrieve/pii/ S0169433203001375

[8] H. Ali-Löytty, P. Jussila, T. Juuti, L. Karjalainen, A. Zakharov, M. Valden, Influence of precipitation on initial high-temperature oxidation of TiNb stabilized ferritic stainless steel SOFC interconnect alloy, Int. J. Hydrogen Energy 37 (19) (2012) 14528-14535 http://linkinghub.elsevier.com/retrieve/pii/ S0360319912017272

[9] R. Somulchowski, Anisotropy of the electronic work function of metals, Phys. Rev. 60 (1941) 661.

[10] D. Funnemann, O. Renault, R. Brochier, A. Roule, P. Haumesser, B. Krömker, Work-function imaging of oriented copper grains by photoemission, Surf. Interface Anal. 38 (2006) 375-377. 
[11] A. Potts, G. Morrison, L. Gregoratti, M. Kiskinova, A. Locatelli, Spectromicroscopy study of the dynamics of submonolayer Pd on a polycrystalline Ni surface, Phys. Rev. B 67 (4) (2003) 045411, http://dx.doi.org/ 10.1103/PhysRevB.67.045411.

[12] M. Escher, K. Winkler, O. Renault, N. Barrett, Applications of high lateral and energy resolution imaging XPS with a double hemispherical analyser based spectromicroscope, J. Electron Spectrosc. Relat. Phenom. 178-179(2010) 303-316.

[13] L.F. Zagonel, M. Bäurer, A. Bailly, O. Renault, M. Hoffmann, S.-J. Shih, D. Cockayne, N. Barrett, Orientation-dependent work function of in situ annealed strontium titanate, J. Phys. Condens. Matter 21 (31) (2009) 314013 http://www.ncbi.nlm.nih.gov/pubmed/21828574
[14] M.C. Biesinger, B.P. Payne, A.P. Grosvenor, L.W. Lau, A.R. Gerson, R.S. Smart, Resolving surface chemical states in XPS analysis of first row transition metals, oxides and hydroxides: Cr, Mn, Fe, Co and Ni, Appl. Surf. Sci. 257 (7) (2011) 2717-2730 http://linkinghub.elsevier.com/retrieve/pii/S0169433210014170

[15] T. Hanawa, S. Hiromoto, A. Yamamoto, D. Kuroda, K. Asami, XPS characterization of the surface oxide film of $316 \mathrm{~L}$ stainless steel samples that were located in quasi-biological environments, Mater. Trans. 43 (12) (2002) 3088-3092 http://joi.jlc.jst.go.jp/JST.JSTAGE/matertrans/43.3088?from=CrossRef

[16] R. Cheng, B. Xu, C.N. Borca, A. Sokolov, C.S. Yang, L. Yuan, S.H. Liou, B. Doudin, P.A. Dowben, Characterization of the native $\mathrm{Cr}_{2} \mathrm{O}_{3}$ oxide surface of $\mathrm{CrO}_{2}$, Appl. Phys. Lett. 79 (19) (2001) 3122, http://dx.doi.org/10.1063/1.1416474. 